\title{
MỘT SỐ LOẠI SƠ ĐỒ Hệ THỐNG HÓA KIẾN THỬC TRONG DẠY HỌC SINH HỌC
}

\section{Some kinds knowledge codification charts in the teaching of biology}

ThS. Ninh Thị Bạch Diệp *

\section{TÓM TẮT}

Trong dạy học, việc hệ thống hóa kiến thức được sử dụng để giáo viên $(\mathrm{GV})$ hệ thống một nội dung nào đó. Đồng thời, GV tổ chức cho học sinh (HS) nghiên cứu các nguồn tài liệu và diễn đạt những thông tin đọc được, xử lý tài liệu đó theo một hướng nhất định để rút ra được những mối quan hệ có tính quy luật giữa các sự vật, hiện tượng. Như vậy, việc hệ thống hóa kiến thức không những giúp HS hình thành được kiến thức mới, củng cố những điều đã học, mà còn biết sắp xếp chúng thành một hệ thống chặt chẽ, đồng thời hình thành kiến thức dưới một góc độ mới, lí giải được ý nghĩa sâu xa của kiến thức, biết cách diễn đạt ý tưởng của mình bằng ngôn ngữ của chính mình.

Từ khóa: hệ thống, hệ thống hóa kiến thức, Graph, bản đồ khái niệm, sơ đồ tư duy.

\begin{abstract}
In teaching, the systemization of knowledge is used for teachers to systemize some matters. At the same time, teachers guide their students to research document and present gathered information in such a certain way in order to figure out the common relationship between things and phenomena. Thus, the systemization of knowledge not only helps students to build up new knowledge and reinforce what they have learned, but also classify them into a coherent system. Furthermore, it helps students to form knowledge under a new form, explain the deep meaning of knowledge and know how to express their ideas in their own way.
\end{abstract}

Keywords: system, Codified knowledge, Graph, Concept maps, Mind map

\section{Khái niệm hệ thống và hệ thống hóa kiến thức}

\subsection{Khái niệm hệ thống}

Hiện nay, có nhiều cách định nghĩa khác nhau về khái niệm hệ thống. Theo L.V. Bertalanffy (1968) cho rằng "hệ thống" là tập hợp các yếu tố liên kết với nhau, tạo thành một chỉnh thể thống nhất và tương tác với môi trường. Miller (1994) lại định nghĩa:"Hệ

\footnotetext{
* Trường Đại học Tân Trào
}

thống là tập hợp các yếu tố cùng với nhũng mối quan hệ tương tác giũa chúng với nhau”. Hoàng Tụy đưa ra khái niệm: "Hệ thống tưc là một tổng thể gồm nhiều yếu tố (bộ phận) quan hệ và tuoong tác với nhau và với môi truờng xung quanh một cách phưc tạp”. Còn tác giả Đào Thế Tuấn lại định nghĩa: "Hệ thống là tập hợp có trật tụ bên trong (hay bên ngoài) của các yếu tố có liên hệ với nhau (hay tác động lẫn nhau)”. Hay Trần Đình Long 
quan niệm: "Hệ thống là một tập hợp có tổ chức các phần tử với nhũng mối liên hệ về cấu trúc và chức năng xác định nhằm thực hiện nhũng muc tiêu cho trước”. Còn theo Từ điển tiếng Việt, hệ thống là tập hợp các yếu tố, đơn vị cùng loại hoặc cùng chức năng, có quan hệ hoặc liên hệ với nhau chặt chẽ làm thành một thể thống nhất.

Như vậy, hệ thống có thể được định nghĩa một cách khái quát như sau: Hệ thống là tập hợp nhiều yếu tố; đon vị cùng loại hoạc cùng chức năng có quan hệ với nhau chặt chẽ làm thành một thể thống nhất.

\subsection{Khái niệm hệ thống hóa kiến thức}

Từ điển tiếng Việt do Hoàng Phê chủ biên nêu khái niệmhệ thống hóa có nghĩa: làm cho trở nên có hệ thống (ví dụ: hệ thống hóa những kiến thức đã học được).

Từ điển tiếng Việt thông dụng do Nguyễn Như Ý chủ biên: "Hệ thống" khi là một danh từ có nghĩa: tập hợp nhiều yếu tố có quan hệ chặt chẽ trong một chỉnh thể (ví dụ: Hệ thống tổ chức); Khi là một động từ thì "hệ thống hóa" có nghĩa: làm cho có hệ thống (ví dụ hệ thống lại các phần đã trình bày).

Trong dạy học, khi tiếp cận với một nguồn thông tin nào đó người ta thường phân tích để sắp xếp chúng theo những quan hệ nhất định tạo thành một tổ hợp hệ thống logic nhờ đó cho ta một kiến thức gọi là hệ thống hoá kiến thức. Như vậy, hệ thống hoá kiến thức là đặt mỗi kiến thức vào đúng tọa độ trong mối quan hệ nhất định. Hệ thống hoá kiến thức là một quá trình thực hiện các thao tác logic để sắp xếp kiến thức vào một hệ thống nhất định để cho một hiểu biết mới sâu sắc về bản chất đối tượng nghiên cứu.

Quá trình dạy học là quá trình tổ chức hoạt động nhận thức. Người học thực hiện hoạt động nhận thức để thu được tri thức bao gồm hệ thống các sự kiện, hiện tượng, các khái niệm, qui luật, nguyên lí, tư tưởng khoa học và cùng với nó là hệ thống các kĩ năng hoạt động nhận thức và thực hành.

Như vậy có thể thấy: Hệ thống hóa là làm cho lớp sụ vật hiện tuợng trở nên hẹ thống, là biện pháp sắp xếp một cách logic các yếu tố, các nội dung thông tin về các đối tuợng, hiện tượng nghiên cúu được chinh thể hóa theo một quan điểm nhất định nhờ đó phản ánh được đầy đủ đặc điểm bản chất về đối tượng đó.

\section{Vai trò của hệ thống hóa trong dạy} học nói chung và dạy học Sinh học nói riêng

Trong dạy học việc hệ thống hóa kiến thức được sử dụng để giáo viên chuẩn bị nội dung tài liệu, sách giáo khoa (SGK) một cách cô đọng nhưng vẫn truyền tải được nhiều thông tin, từ đó tổ chức HS lĩnh hội kiến thức một cách sâu sắc. Với công cụ đó, $\mathrm{GV}$ tổ chức cho HS nghiên cứu các nguồn tài liệu và diễn đạt những thông tin đọc được, xử lý chúng theo một định hướng nhất định để rút ra được những kiến thức mới về tính chất, mối quan hệ có tính quy luật giữa các sự vật và hiện tượng. Hệ thống hóa kiến thức giúp HS chuyển các kiến thức từ tái hiện giáo khoa thành tri thức mang tính hệ thống, thu nạp theo một qui trình cá nhân nhận thức phù hợp được chiết xuất từ năng lực của người học.

Trong dạy học việc hệ thống hóa kiến thức sẽ có tác dụng rèn luyện HS những phẩm chất trí tuệ như:

- Rèn luyện kĩ năng đọc tóm tắt tìm ra ý chính, cơ bản, cốt lõi nhất trong tài liệu, SGK; đồng thời thiết lập được mối quan hệ giữa các thành phần kiến thức. Quá trình này đòi hỏi HS phải vận dụng thành thạo các thao tác tư duy cơ bản như: so sánh, phân tích, tổng hợp, khái quát, trừu tượng hoá, xác lập các mối quan hệ, diễn đạt nội dung bằng những hình 
thức ngôn ngữ khác nhau, ... Đây là quá trình xử lý thông tin chuyển hoá tri thức sách vở thành kiến thức của bản thân. Như vậy, việc hệ thống hóa kiến thức giúp HS sử dụng được các nguồn tài liệu đa dạng, phát triển tư duy logic, tư duy hình tượng, tư duy biện chứng.

- Qua việc hệ thống hóa kiến thức, HS biết cách đối chiếu, so sánh sự vật hiện tượng để tìm ra quy luật, nghĩa là rèn luyện HS khả năng khái quát hoá rút ra kết luận.

- Việc hệ thống hóa kiến thức còn giúp cho $\mathrm{HS}$ vừa chiếm lĩnh kiến thức, vừa hình thành phương pháp để đi tới chiếm lĩnh kiến thức cho bản thân, phát triển năng lực tiếp nhận và giải quyết vấn đề, năng lực tự học và thói quen tự học, sáng tạo, giúp cho HS có thể tự học suốt đời. Đây là một trong những yêu cầu căn bản của lí luận dạy học nói chung và lí luận dạy học Sinh học nói riêng.

Đối với bộ môn Sinh học, kiến thức cơ bản nhất là hệ thống các khái niệm, các quy luật sinh học liên hệ chặt chẽ với nhau, được hình thành và phát triển theo một trật tự logic. Việc giảng dạy các khái niệm hay các quy luật đó không chỉ để HS nắm vững nội hàm của khái niệm hay quy luật mà còn phải làm cho HS biết cách sắp xếp các khái niệm và các quy luật đó vào hệ thống các khái niệm và quy luật đã có. Nhờ đó giúp HS có được tư duy hệ thống, dễ dàng lĩnh hội và khắc sâu kiến thức. Do vậy, việc giúp cho người học có khả năng cũng như thói quen hệ thống hóa lại càng có vai trò quan trọng.

Như vậy, việc hệ thống hóa kiến thức giúp HS tìm kiến thức mới, củng cố những điều đã học, sắp xếp chúng thành một hệ thống chặt chẽ, đồng thời hình thành kiến thức dưới một góc độ mới, biết cách diễn đạt ý tưởng của mình bằng ngôn ngữ của chính mình khi nghiên cứu nội dung kiến thức Sinh học. Hệ thống hóa kiến thức chỉ thực hiện được trên cơ sở thông tin được xử lý qua phân tích, tổng hợp. Như vậy, việc rèn luyện cho HS kĩ năng hệ thống hóa kiến thức trong dạy học nói chung và dạy học Sinh học nói riêng là rất quan trọng. Vì vậy, việc sử dụng các bảng biểu hay các sơ đồ làm công cụ để hệ thống hóa kiến thức là việc làm cần thiết mà GV phải hướng dẫn cho HS trước khi yêu cầu HS hệ thống hóa kiến thức.

\section{Một số loại so đồ được sử dụng để hệ thống hóa kiến thức trong dạy học Sinh học}

\section{kiến thức}

\subsection{Sủ dụng graph để hệ thống hóa}

Theo Từ điển Anh - Việt, graph có nghĩa là đồ thị - biểu đồ gồm có một đường hoặc nhiều đường biểu diễn sự biến thiên của các đại lượng. Nhưng từ Graph trong lý thuyết Graph lại bắt nguồn từ "Graphic" có nghĩa tạo ra một hình ảnh rõ ràng, chi tiết, sinh động trong tư duy.

Graph có nguồn gốc là một trong những lý thuyết thuộc chuyên ngành của toán học, sau đó nó đã được nghiên cứu trong các lĩnh vực khoa học khác. Trên thế giới và ở Việt Nam đã có nhiều tác giả nghiên cứu chuyển hóa Graph toán học vào dạy học với vai trò như một tiếp cận dạy học.

Graph được định nghĩa dựa trên hai tập hợp. Tập hợp các đỉnh và tập hợp các cạnh (cung). Như vậy, điều kiện để lập một graph phải có hai yếu tố: tập hợp các đỉnh và tập hợp các cung. Mỗi cung lại là tập hợp của hai đỉnh có quan hệ với nhau, hai đỉnh không quan hệ với nhau không lập thành một cung của graph.

Đỉnh của graph biểu thị một nội dung hoặc một đối tượng nghiên cứu. Các đỉnh của graph có thể được ký hiệu bằng một chữ cái (A, B, C...), một dấu chấm, một hình chữ nhật, một hình vuông, hay một hình tròn... 
Đỉnh được kí hiệu theo cách nào không quan trọng vì không quyết định bản chất của graph. Các cung của graph: Là đường nối các đỉnh của graph, biểu thị mối quan hệ giữa các đỉnh trong graph. Các cung của graph cũng được thể hiện tương đối tự do có thể được biểu diễn bằng một đoạn thẳng, đường cong,... Độ dài cung có thể dài, ngắn, to nhỏ, đậm nhạt khác nhau, việc thể hiện cung bằng hình thức nào hoàn toàn không làm thay đổi bản chất của graph. Cách kí hiệu các đỉnh và cách biểu diễn các cung không làm thay đổi bản chất của graph. Cái quyết định bản chất của graph là ở số lượng các đỉnh, số lượng các cung và mối quan hệ của chúng trong graph đó.

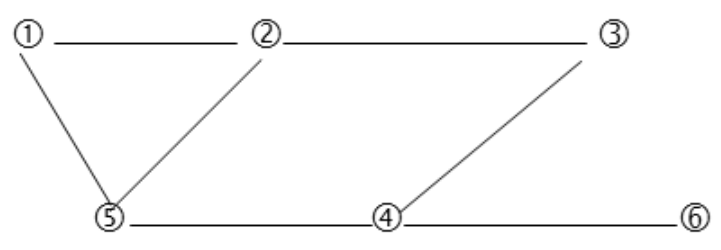

Hình 1. Graph với 6 đỉnh và 7 cạnh

Graph được dùng để hệ thống hoá các khái niệm trong các tài liệu học tập nhằm mã hoá và trực quan hoá các mối quan hệ của các thành phần kiến thức, Graph được dùng để cấu trúc hoá nội dung của tài liệu giáo khoa và Graph dùng để hướng dẫn HS tự học.

\subsection{Sủ dụng bản đồ khái niệm để hệ thống hóa kiến thức}

Bản đồ khái niệm (Concept maps) là công cụ dạng sơ đồ, dùng để sắp xếp và trình bày kiến thức. Chúng bao gồm các khái niệm và các từ (hoặc các cụm từ) liên kết chỉ mối quan hệ giữa các khái niệm. Các khái niệm thường được đóng khung trong các hình tròn hay các hình chữ nhật, mối quan hệ giữa các khái niệm được thể hiện dưới dạng đường nối giữa hai khái niệm. Đường nối đại diện cho mối quan hệ giữa các khái niệm, có gắn nhãn nhằm miêu tả rõ ràng hơn mối quan hệ đó. Nhãn thường là từ nối hay các cụm từ nối, định rõ mối quan hệ giữa hai khái niệm. Phần lớn nhãn của các khái niệm là một danh từ, đôi khi sử dụng các ký hiệu như “+” hay “\%”.

Như vậy, bản đồ khái niệm bao gồm các "nút" tượng trưng cho các khái niệm và các đường liên kết tượng trưng cho mối quan hệ giữa các khái niệm. Những khái niệm được sắp xếp theo trật tự logic, mỗi khái niệm là một nhánh của bản đồ.

Các bản đồ khái niệm có cấu trúc thứ bậc, khái niệm chung nhất, tổng quát nhất được xếp ở đỉnh của bản đồ, các khái niệm cụ thể hơn được xếp ở bên dưới. Cấu trúc thứ bậc cho một lĩnh vực kiến thức riêng biệt còn phụ thuộc vào ngữ cảnh trong đó nội dung kiến thức đang được áp dụng hay xem xét.

Đặc trưng quan trọng khác của bản đồ khái niệm là đường liên kết chéo (crosslinks). Đường nối này thể hiện mối quan hệ giữa các khái niệm trong những lĩnh vực khác nhau của bản đồ khái niệm. Đường liên kết chéo giúp chúng ta thấy một số lĩnh vực kiến thức trên bản đồ liên quan với nhau như thế nào. Trong sự tạo thành kiến thức mới, đường liên kết chéo thường thể hiện sự sáng tạo của người thiết kế bản đồ.

Phần cốt lõi của bản đồ khái niệm là mệnh đề (propositions). Mệnh đề là sự phát biểu về sự vật hay sự kiện nào đó diễn ra một cách tự nhiên hoặc nhân tạo. Mệnh đề gồm hai khái niệm (hoặc nhiều hơn) nối với nhau bởi một đường nối có nhãn nhằm tạo nên lời phát biểu có ý nghĩa. Đôi khi mệnh đề còn được gọi là những đơn vị ngữ nghĩa. Những mệnh đề là nhân tố làm cho bản đồ khái niệm khác với những tổ chức đồ thị tương tự khác.

Ngoài ra, trong bản đồ khái niệm có thể có các ví dụ ở cuối khái niệm, chúng có vai trò trợ giúp để làm rõ ý nghĩa của khái niệm đó. Các ví dụ cũng được bao quanh bởi hình tròn, elip hoặc hình chữ nhật nhưng nét vẽ đứt. 


\subsection{Sủ dụng sơ đồ tư duy để hệ thống}

\section{hóa kiến thức}

Theo Tony Buzan, người đầu tiên tìm hiểu và sáng tạo ra sơ đồ tư duy thì: sơ đồ tư duy là một hình thức ghi chép sử dụng màu sắc và hình ảnh, từ khóa để mở rộng và đào sâu các ý tưởng. Ở giữa sơ đồ là một ý tưởng hay một hình ảnh trung tâm. Ý tưởng hay hình ảnh trung tâm này sẽ được phát triển bằng các nhánh tượng trưng cho các ý chính và đều được nối với các ý trung tâm. Với phương thức tiến dần từ trung tâm ra xung quanh, sơ đồ tư duy khiến tư duy con người cũng phải hoạt động tương tự. Từ đó các ý tưởng của con người sẽ phát triển.

Sơ đồ tư duy là một hình thức ghi chép sử dụng màu sắc và hình ảnh, để mở rộng và đào sâu các ý tưởng. Trong đó, tư duy của con người được thể hiện dưới dạng sơ đồ, bản đồ (hình 2).

Một sơ đồ tư duy thông thường có cấu trúc gồm hai phần chính: các hình ảnh (hay từ khóa) và các đường nối liên kết chúng với nhau. Ở vị trí trung tâm sơ đồ là một hình ảnh hay một từ khóa thể hiện một ý tưởng hay khái niệm chủ đạo. Ý trung tâm sẽ được nối với các hình ảnh hay từ khóa cấp 1 bằng các nhánh chính, từ các nhánh chính lại có sự phân nhánh đến các từ khóa cấp 2 để nghiên cứu sâu hơn.
Cứ thế, sự phân nhánh cứ tiếp tục và các khái niệm hay hình ảnh luôn được nối kết với nhau. Chính sự liên kết này sẽ tạo ra một "bức tranh tổng thể" mô tả về ý trung tâm một cách đầy đủ và rõ ràng. Việc tạo ra các sơ đồ tư duy như thế nào là tùy thuộc vào chủ thể hay nói cách khác là tùy thuộc vào tư duy của từng cá nhân.

Trong sơ đồ tư duy, hình ảnh hay từ khóa thể hiện chủ đề của sơ đồ được đặt ở vị trí trung tâm, các ý khác tỏa ra xung quanh, điều này được Tony Buzan giải thích dựa trên những cơ sở nghiên cứu của ông về hoạt động của bộ não. Các từ khóa trên sơ đồ có thể được thể hiện bởi các hình ảnh, mật mã, ký hiệu... và đường nối thường được biểu thị bằng rất nhiều màu sắc, điều này giống như một cách kích thích cho các bán cầu não cùng hoạt động phối hợp với nhau và tạo hứng thú cho người vẽ cũng như người sử dụng sơ đồ tư duy đó.

Sơ đồ tư duy được sử dụng rộng rãi trong nhiều lĩnh vực đời sống, kinh tế, xã hội, như kinh doanh, lập kế hoạch, thiết kế chiến lược phát triển.... Việc sử dụng các phần mềm mind mapping sẽ làm cho công việc lập sơ đồ tư duy dễ dàng và linh hoạt hơn.

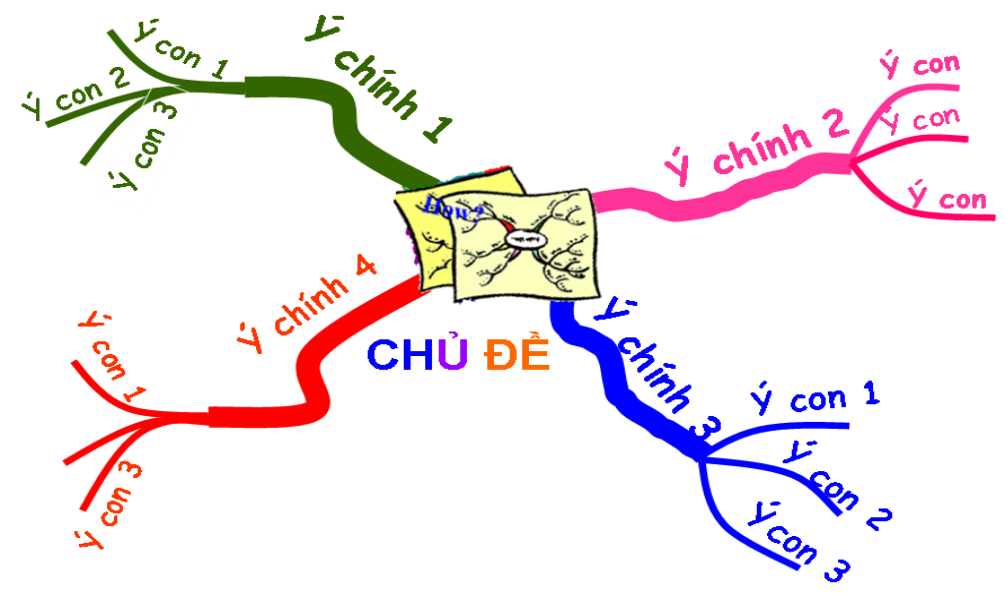

Hình 2. Cấu trúc của bản đồ tư duy 


\section{hóa kiến thức}

\subsection{Quy trình xây dụng sơ đồ hệ thống}

\section{hóa kiến thức}

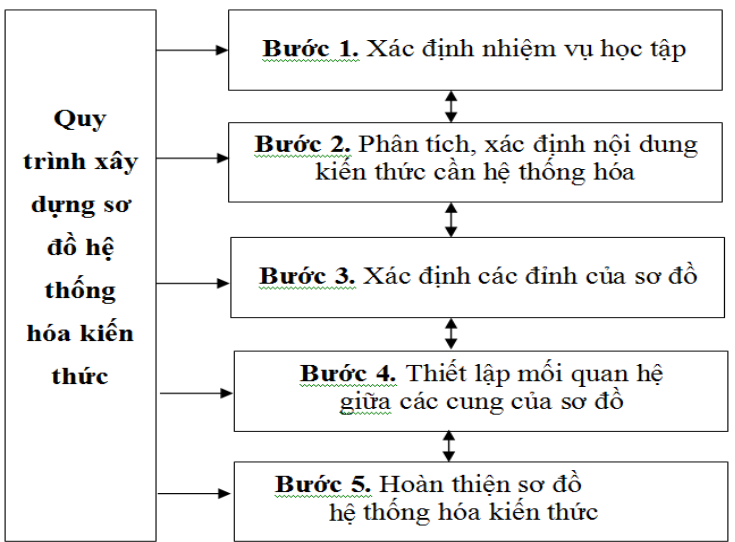

Hình 3. Quy trình xây dưng sơ đồ hệ thống hóa kiến thức

Giải thích các bước:

\section{Bước 1: Xác định nhiệm vụ học tập}

Trong bước này HS phải xác định rõ những hoạt động học tập của bản thân phải thực hiện và những điều kiện cần có để thực hiện hoạt động đó. Muốn HS thực hiện được nhiệm vụ này, GV phải kết hợp các phương pháp sư phạm khác nhau tác động vào mọi giác quan của người học để tạo động cơ, nhu cầu muốn giải quyết các vấn đề mà $\mathrm{GV}$ đưa ra thì việc hệ thống hóa kiến thức cho HS mới có hiệu quả.

Bước 2: Phân tích, xác định nội dung kiến thức cần hệ thống hóa

Sau khi GV hình thành cho HS động cơ, nhiệm vụ học tập, GV tiếp tục định hướng cho HS xác định những kiến thức trọng tâm dựa vào những tiêu chí mà $G V$ đưa ra. Để thực hiện bước này, $\mathrm{GV}$ cần định hướng cho $\mathrm{HS}$ bằng các câu hỏi gợi ý, hướng dẫn HS đọc SGK, quan sát, phân tích tài liệu tham khảo, tranh ảnh và video. Từ những gợi ý này, HS sẽ xác định được những nội dung kiến thức trọng tâm cần được hệ thống hóa.

\section{Bước 3: Xác định các đỉnh của so đồ}

Phân tích, xác định nội dung kiến cơ bản nhất chọn làm kiến thức chốt. Mỗi kiến thức chốt sẽ là một đỉnh của sơ đồ. Có thể gộp những kiến thức chốt cùng tính chất, cùng thể loại về ý nghĩa và nội dung vào chung một đỉnh.

Mã hóa kiến thức chốt. Có thể sử dụng những kí hiệu dễ hiểu nhất để mã hóa kiến thức chốt, như vậy sẽ giúp HS dễ dàng ghi nhớ hơn và sơ đồ cũng bớt phần cồng kềnh. Bố trí các đỉnh trên mặt phẳng. Cần lưu ý sắp xếp các đỉnh sao cho có tính khoa học, phản ánh được logic phát triển của kiến thức, dễ hiểu và phải có tính trực quan mỹ thuật.

\section{Bước 4. Thiết lập mối quan hệ giữa} các cung của sơ đồ

Sau khi xác định kiến thức chốt, cần xác định mối liên hệ phụ thuộc giữa nội dung các đỉnh với nhau, bằng cách nối các đỉnh bằng mũi tên hay đoạn thẳng, sao cho phản ánh được logic phát triển của nội dung đó để hình thành các cung của sơ đồ.

\section{Bước 4: Hoàn thiện sơ đồ hệ thống hóa kiến thức}

Sau khi xác định được mối quan hệ giữa các nội dung kiến thức, HS phải trình bày được mối quan hệ giữa các nội dung kiến thức được hệ thống hóa bằng việc hoàn thiện các sơ đồ theo một trật tựlogic nhất định.

3.2. Yêu cầu của sơ đồ hệ thống hóa kiến thức

Tuy nhiên, khi sử dụng sơ đồ để hệ thống hóa kiến thức thì sơ đồ đó cũng phải đảm bảo một số yêu cầu sau: 
- Sơ đồ hệ thống hóa kiến thức phải thực hiện mục tiêu của bài học.

- Sơ đồ hệ thống hóa kiến thức phải đảm bảo tính khoa học, chính xác, logic và mang tính sư phạm cao.

- Sơ đồ hệ thống hóa kiến thức phải đảm bảo sự liên hệ chặt chẽ giữa các thứ bậc và trong các thành phần của một thứ bậc thuộc một cấp độ tổ chức của thế giới sống.
- Sơ đồ hệ thống hóa kiến thức phải bao quát được nội dung cơ bản về kiến thức cần hệ thống ở SGK.

- Sơ đồ hệ thống hóa kiến thức phải dễ hiểu, không quá phức tạp, phù hợp với trình độ của HS.

\subsection{Ví du minh họa}

Sơ đồ hệ thống hóa kiến thức phần nhân đôi ADN (Sinh học 12) dưới dạng bản đồ khái niệm, graph và sơ đồ tư duy.

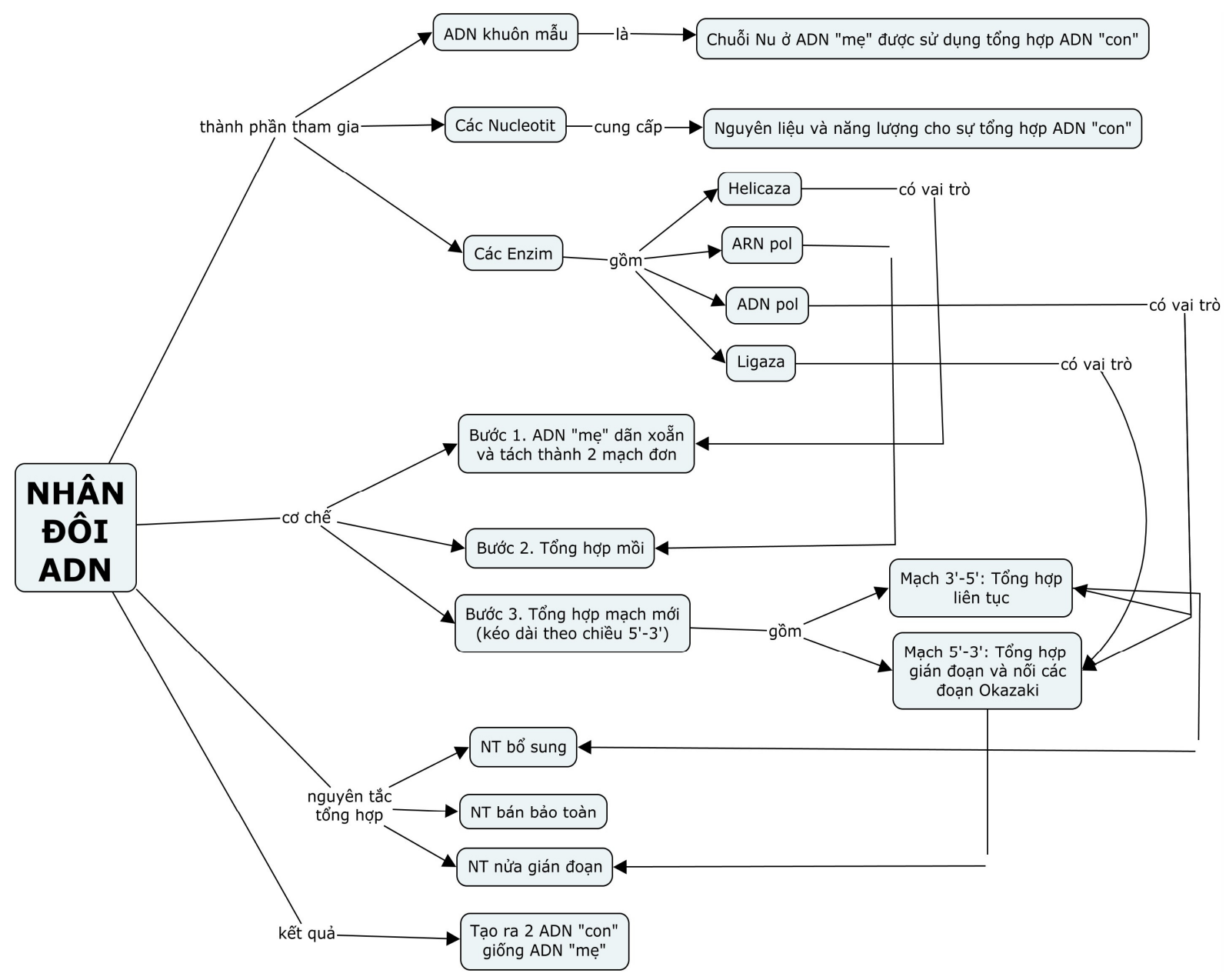

Hình 4. Bản đồ khái niệm về nhân đôi $A D N$ 


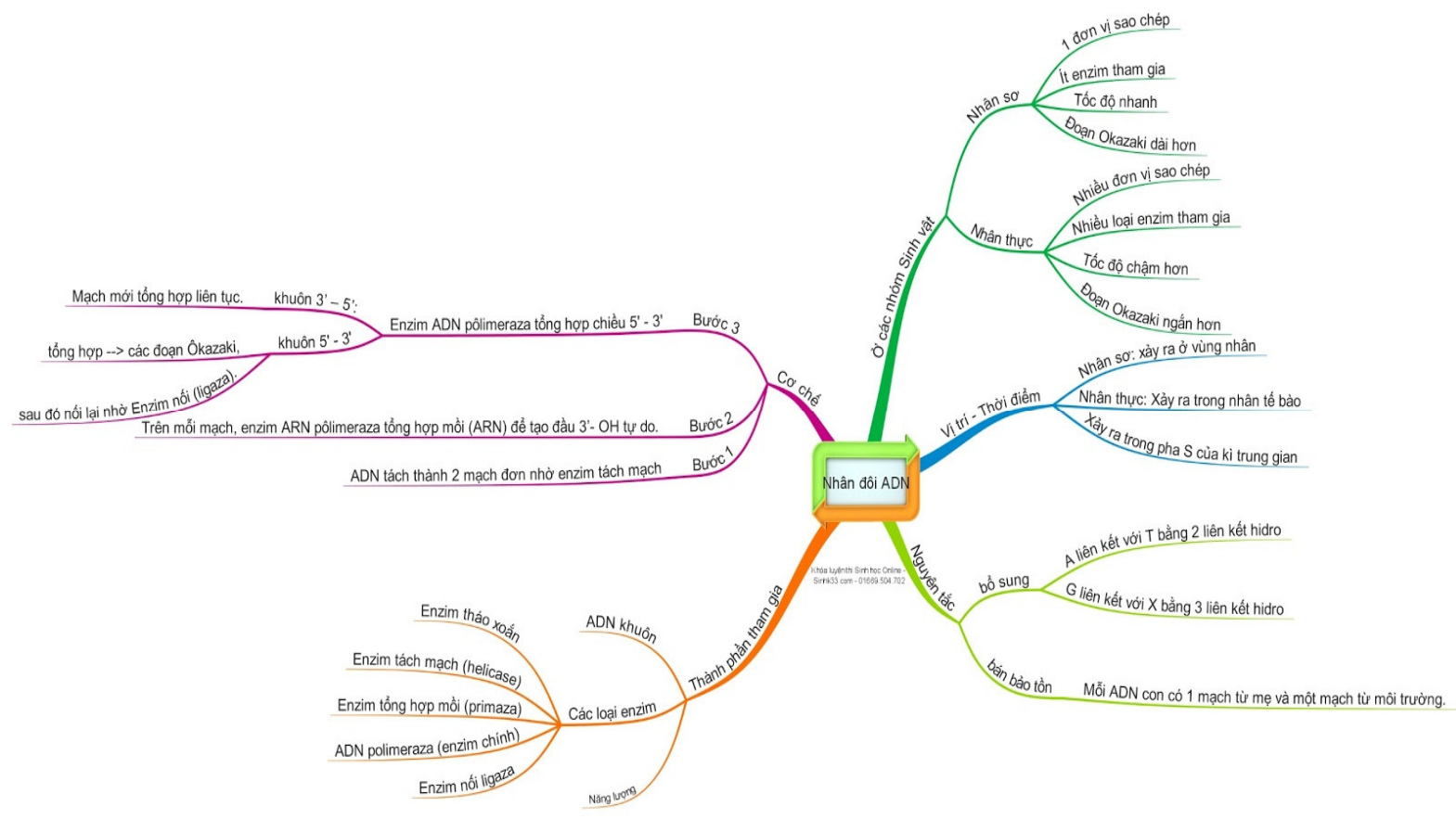

Hình 5. So đồ tu duy về nhân đôi $A D N$

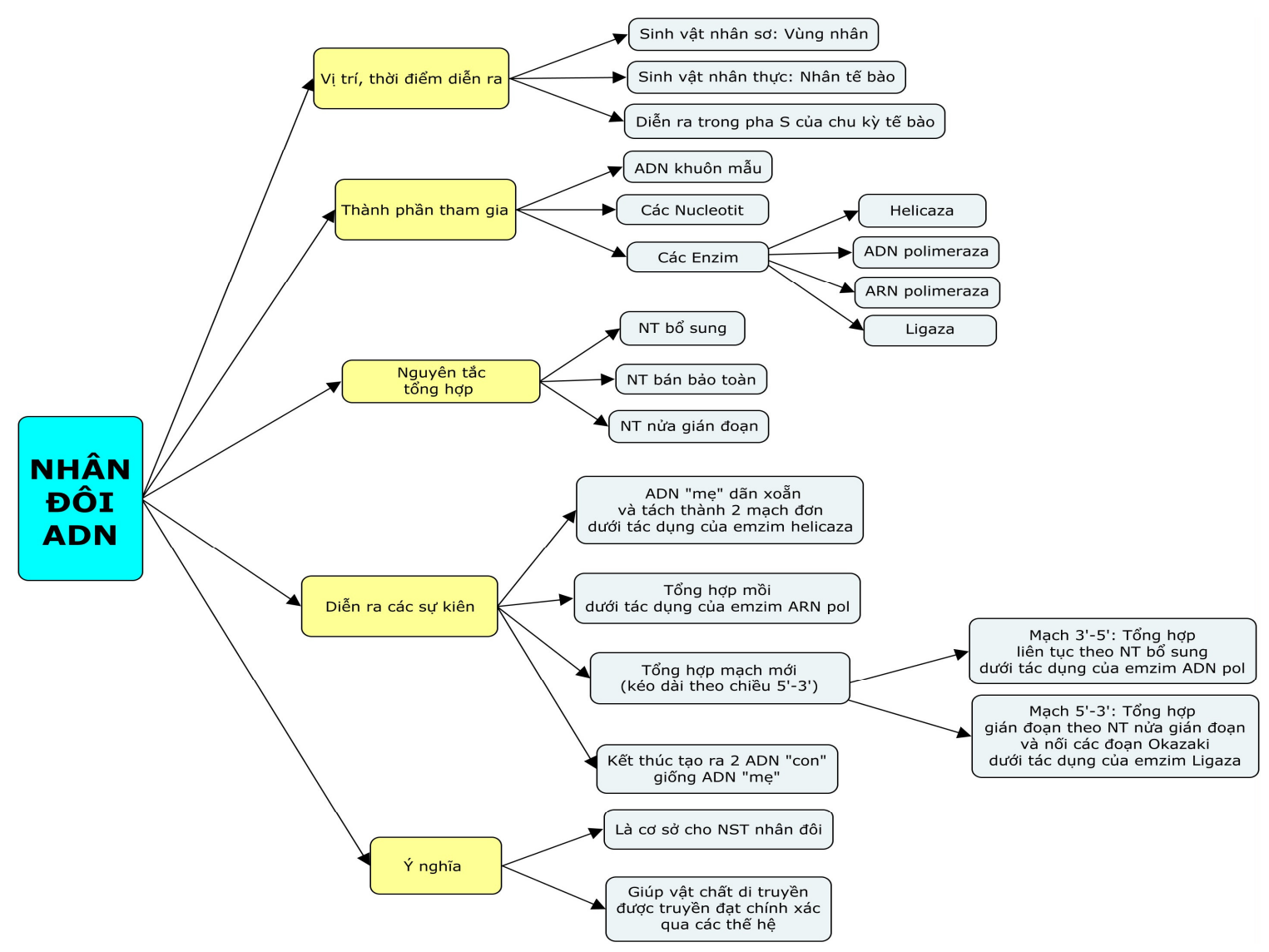

Hình 6. Graph về nhân đôi $A D N$ 
Tóm lại: Hệ thống hóa kiến thức có vai trò hết sức to lớn đối với cả $\mathrm{GV}$ và $\mathrm{HS}$ trong quá trình tổ chức dạy học. Đối với $G V$, hệ thống hóa kiến thức góp phần nâng cao kết quả giảng dạy, năng lực chuyên môn, yêu nghề và tâm huyết hơn với hoạt động sư phạm. Đối với HS, khi kiến thức được hệ thống hóa đã tạo ra tính trực quan, hình thành biểu tượng sơ đẳng về kiến thức đó, từ đó, giúp các em dễ dàng nắm bắt kiến thức, hiểu sâu kiến thức, vận dụng sáng tạo, linh hoạt, chủ động các kiến thức đã học từ đó nâng cao hiệu quả học tập môn học. Vì vậy, trong dạy học nói chung và dạy học Sinh học nói riêng GV cần hướng dẫn HS những kỹ năng cơ bản để HS biết hệ thống hóa kiến thức trong dạy học bộ môn

\section{TÀI LIỆU THAM KHẢO}

1. Nguyễn Phúc Chỉnh (2005), Phương pháp Graph trong dạy học Sinh học, Nxb Giáo dục, Hà Nội.

2. Nguyễn Phúc Chỉnh, Phạm Thị Hồng Tú (2011), "Thiết kế bản đồ khái niệm phần Di truyền học-Sinh học 12”, Tạp chí Giáo dục (265).

3. Tony Buzan (2009), So đồ tu duy, Nxb Lao động xã hội, Hà Nội. 